\title{
A validation of an operational wave and surge prediction system for the Dutch coast
}

\author{
L. Sembiring ${ }^{1,2}$, M. van Ormondt ${ }^{2}$, A. van Dongeren ${ }^{2}$, and D. Roelvink ${ }^{1,2}$ \\ ${ }^{1}$ UNESCO-IHE Institute for Water Education, Delft, the Netherlands \\ ${ }^{2}$ Deltares, Delft, the Netherlands \\ Correspondence to: L. Sembiring (1.sembiring@unesco-ihe.org)
}

Received: 12 March 2014 - Published in Nat. Hazards Earth Syst. Sci. Discuss.: 9 May 2014

Revised: 21 May 2015 - Accepted: 22 May 2015 - Published: 16 June 2015

\begin{abstract}
Knowledge of the actual condition of hydrodynamics in the nearshore and coastal area is essential for coastal monitoring activities. To this end, a coastal operational model system can serve as a tool in providing recent and up-to-date, state-of-the-art hydrodynamics along the coast. In this paper, we apply CoSMoS (Coastal Storm Modeling System), a generic operational wave and tide-surge modelling system applied here to predict waves and water levels along the Dutch coast. The CoSMoS application is not limited to storm impact prediction on the Dutch coast, but can also be applied to other coastal hazards such as rip currents and coastal flooding, in other environments. In this paper, we present the set-up of the CoSMoS system and a validation of the wave and surge model, with deep-water wave buoy data and tidal gauge measurements as ground truth validation material. The evaluation is presented as monthly error measures between computed parameters and observed ones. Hindcast results over the whole year of 2009 show that the simulated wave parameters and surge elevation from the CoSMoS are in good agreement with data, with average root mean square (rms) error over the year of $0.14 \mathrm{~m}$ for the surge elevation and $0.24 \mathrm{~m}$ for the significant wave height. It is noted that there is a tendency of the wave model to underestimate the height of northerly waves with lower frequencies (swell). Additionally, when a wave separation algorithm is applied on the overall spectrum, results show consistent underestimation of the swell component by the model, which for the Dutch coast will mainly come from the north, where the North Sea is open to the Atlantic Ocean. In the proposed model system, the swell boundary can have a significant effect on the simulated wave results, suggesting room for improvement for the swell boundary conditions to the north and the swell propa-
\end{abstract}

gation within the Dutch Continental Shelf Model. Finally, we show that in forecast mode, CoSMoS can provide reasonably good wave and surge prediction.

\section{Introduction}

Knowledge of the actual condition of nearshore and coastal hydrodynamics is an essential point in coastal risk management and monitoring activities. Using this knowledge, the risk of coastal hazards, such as coastal inundation, beach and dune erosion, and rip currents can be predicted and mitigated. To this end, a coastal operational model system can serve as a key tool in providing recent and up-to-date information about the hydrodynamic and morphodynamic state of the coast. Output from such a model system can be valuable for coastal stake holders and decision makers. In this paper, we present validation results of CoSMoS (Coastal Storm Modeling System; Baart et al., 2009; Barnard et al., 2009; Van Ormondt et al., 2012), an operational coupled wave and tide-surge modelling system. The CoSMoS model system is generic, and its application is not limited to storm events, but can also be used for daily condition applications such as operational workable weather forecast for marine and offshore industry, as well as for rip-current predictions for swimmer safety application. Nowadays, many models are already available with which coastal processes and circulation can be simulated (Stelling, 1984; Van Dongeren et al., 1994; Wei et al., 1995; Roelvink et al., 2009). Model systems like CoSMoS can provide such coastal models with boundary information from larger area models in an efficient way and with low logistical efforts. In addition, meteorological data as input for CoSMoS can 
Table 1. List of variables used in the paper.

\begin{tabular}{lll}
\hline Variable & Description & Unit \\
\hline$e_{\mathrm{rms}}$ & Root mean square error & $\mathrm{m}$ (wave height) \\
& & $\mathrm{s}$ (wave period) \\
$e_{\mathrm{norm}}$ & Normalized root mean square error & - \\
$\mathrm{CC}$ & Circular correlation & - \\
$\mathrm{CB}$ & Circular bias & degree \\
$R$ & Mean resultant vector of the plane component (directional data) & - \\
$E$ & Variance density spectrum & $\mathrm{m}^{2} \mathrm{~Hz}^{-1}$ \\
$\theta$ & Wave direction & degree \\
$f$ & Wave frequency & $\mathrm{Hz}$ \\
$H_{\mathrm{s}}, H_{m} 0$ & Wave height & $\mathrm{m}$ \\
$T_{\mathrm{p}}$ & Peak wave period & second \\
$\sigma$ & Directional width of the wave spectrum (Gaussian function) & degree \\
$f_{\mathrm{c}}$ & Critical frequency between swell and wind sea energy & $\mathrm{Hz}$ \\
$\delta$ & Angle between wind sea and swell & degree \\
$U$ & Wind speed & $\mathrm{ms}$ \\
$\alpha$ & Constant in wave separation algorithm & - \\
\hline
\end{tabular}

Table 2. Model set-up for DCSM

\begin{tabular}{lll}
\hline & SWAN & Delft3D Flow \\
\hline Grid size & $\sim 15 \times 20 \mathrm{~km}^{2}$ & $\sim 7.5 \times 10 \mathrm{~km}^{2}$ \\
Open boundary & WAVEWATCH III Global & Tide model TPX072 \\
Meteo input & HIRLAM & HIRLAM \\
Source term: & Westhuysen et al. (2007) & - \\
Wind growth & Westhuysen et al. (2007) & \\
Whitecapping & JONSWAP & \\
Bottom friction & (Hasselman et al., 1973) & \\
Depth-induced breaking & Battjes and Janssen (1978) & \\
\hline
\end{tabular}

be obtained from well-established meteorological models, most of which are run in operational mode, e.g. GFS (Global Forecast System, operated by National Oceanic and Atmospheric Administration, USA), HIRLAM (High-resolution limited area model; Unden et al., 2002), and ECMWF (European centre for medium-range weather forecast; Janssen et al., 1997).

Application of such model systems for wave forecasting has been demonstrated previously. On a global scale, Hanson et al. (2009) presented a skill assessment of three different regional wave models: WAM (Gunther, 2002), WAVEWATCH III (Tolman, 2009), and WAVAD (Resio and Perrie, 1989). They performed multi-decadal hindcasts for the Pacific Ocean, and found that in general, all three models show good skill, with WAVEWATCH III performing slightly better than the other two. For semi-enclosed basin scale modelling, some studies show that wave conditions can be well simulated in serious storm events (Mazarakis et al., 2012; Bertotti et al., 2011; Bertotti and Cavaleri, 2009; Cherneva et al., 2008). However, the quality of the wave model decreases substantially when the wind condition shows strong temporal and spatial gradients. This is particularly true for
Table 3. Model version and parameter settings.

\begin{tabular}{ll}
\hline \multicolumn{2}{c}{ SWAN, model version 4072} \\
Source term & Value \\
\hline Whitecapping; Westhuysen et al. (2007) & 0.00175 \\
$B_{\mathrm{R}}$ (threshold saturation level) & 0.00005 \\
$\mathrm{C}_{\mathrm{ds}}^{\prime}$ (proportionality coefficient) & \\
Bottom friction; Hasselman et al. (1973) & $0.067 \mathrm{~m}^{2} \mathrm{~s}^{-3}$ \\
C(bottom friction coefficient) & \\
Depth-induced breaking; & 0.73 \\
Battjes and Janssen (1978) & 1.0 \\
Gamma (breaker parameter) & \\
Alpha (dissipation coefficient) & \\
DELFT 3D FLOW, model version 4.01 & \\
Bed roughness Chezy coefficient & $90 \mathrm{~m}^{1 / 2} \mathrm{~s}^{-1}$ \\
Wind drag coefficient A, B, C & 0.00063, \\
(see Delft3D User Manual) & 0.00723, \\
& 0.00723 \\
\hline
\end{tabular}


enclosed basins where an underestimation of wind speed by the atmospheric model is often found (Ponce de Leon and Soares, 2008; Cavaleri and Bertotti, 2004, 2006). In addition, wave models are very sensitive to small variations within the wind fields which act as forcing input (Bertotti and Cavaleri, 2009). Moreover, Cherneva et al. (2008) reported an underestimation by the WAM Cycle 4 model of significant wave heights in the case of low wind energy input and during combined swell-wind wave conditions. In contrast, the model shows relatively better performance for the case of high energy input. For the North Sea area, Behrens and Gunther (2009) demonstrated that the WAM model that covers the North Sea and Baltic Sea was capable to provide a forecast 2 days ahead of the winter storms Britta and Kyrill in 2006 with satisfactory results. As improvements to the model, they suggest further development on the atmospheric model (developed by the German Weather Service). In addition to that, the model does not take into account depth-induced wave breaking as one of the source terms in the model equation, which is a required further improvement necessary for a nearshore prediction system (Behrens and Gunther, 2009). The application of model systems for storm surge and tide prediction has also been demonstrated. For the Netherlands, Verlaan et al. (2005) make use of the hydrodynamic model, DCSM (Dutch Continental Shelf Model; Gerritsen et al., 1995) and forced it using meteorological model HIRLAM, to provide tide and storm surge forecasts. Moreover, they implemented an update to the Kalman filter configuration to improve quality of forecast, initially implemented by Heemink and Kloosterhuis (1990). This approach now has been applied in the operational prediction system DelftFEWS (Delft - Flood Early Warning System; Werner et al., 2013), which has flexibility in integrating different models and data in a comprehensive way to provide forecast information. Specifically for coastal forecasting, De Kleermaeker et al. (2012) present an operational model system for the Dutch coast under the framework of the FEWS system, combining data from different sources to provide a reliable forecast. They use the hydrodynamic model of Delft3D-FLOW to compute tides and surge and SWAN (Booij et al., 1999) for the waves. Preliminary results from the model system give a wave height bias of $10 \%$ and rms error of $3.7 \mathrm{~cm}$ for the water levels.

Coupling wave and tide-surge modelling has been found to be an important key to improve prediction skill of water level and waves (Brown and Wolf, 2009; Wolf, 2009). Application of this coupling approach for the Mediterranean Sea using a 3-D finite element hydrodynamic model SHYFEM shows that the modelling system Kassandra predicts water level and wave height very well, with the rms error range of $\sim 4$ until $8 \mathrm{~cm}$ and $\sim 22$ until $33 \mathrm{~cm}$ for total water level and wave height, respectively (Ferrarin et al., 2013). A similar approach has also been implemented for the Irish Sea by Brown et al. (2010), where they use the one-way nested approach of the North Atlantic model and the Irish Sea region.

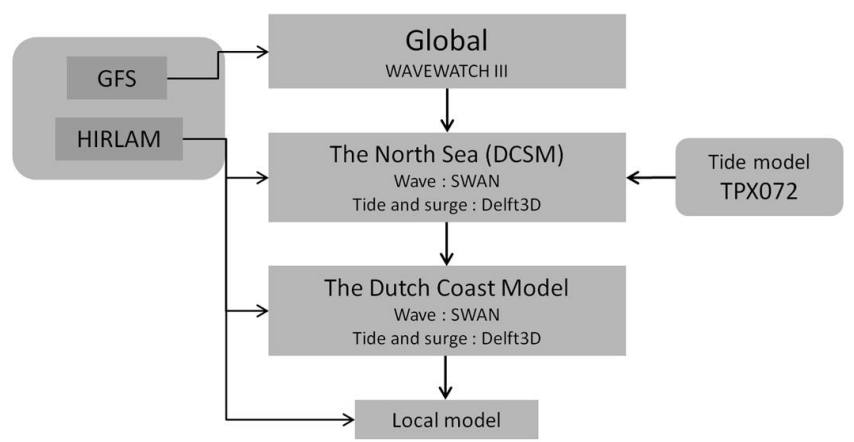

Figure 1. Model and domain structure within the Coastal Storm Modeling System - CoSMoS.

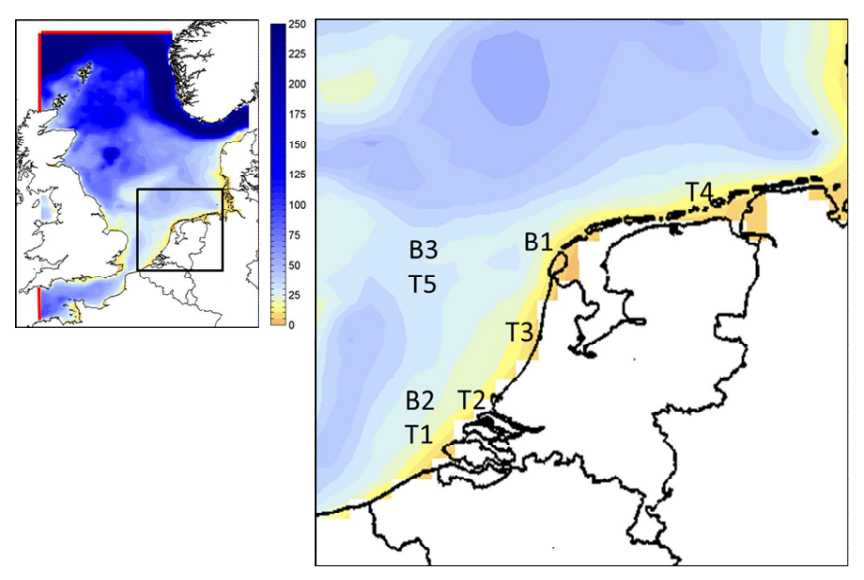

Figure 2. The North Sea (left), with the colour shading represents depth. Red lines indicate the swell boundary for the wave model. The Dutch coast (right), and stations used in analysis (see Table 4).

Using WAM as spectral wave model and the POLCOMS model (Proudman Oceanographic Laboratory Coastal-Ocean Modelling System) as tide-surge model, they show that the coupled scheme performs very well at predicting total water level and waves. They make use of a statistical measure called percentage model bias (PBias) to evaluate the skill of the model, and found that model system gives PBias of 14 until $37 \%$ for significant wave height (Brown et al. (2010) classify the PBias as follows: less than $10 \%$ excellent, 10 $20 \%$ very good, $20-40 \%$ good, and greater than $40 \%$ poor).

In this paper, the CoSMoS application to the North Sea basin and validation will be presented. It is a coupled wave and tide-surge modelling approach with nested spatial domain starting from the global model to the North Sea. The validation will be on the wave parameters, water level, and surge elevation simulated by the model, focusing on the North Sea. This paper is organized as follows: Sect. 2 describes the CoSMoS set-up and description of models within it. Section 3 briefly describes methodologies and data that are used in the paper. In Sect. 4, results of the validation will be presented and discussed, and conclusions will be drawn 
in Sect. 5. A list of variables used in the paper are shown in Table 1.

\section{The CoSMoS model system}

The CoSMoS system is set up for the North Sea basin, where regional wave and tide-surge models are integrated with local (high-resolution) models (Baart et al., 2009; van Ormondt et al., 2012). The model and domain structure of CoSMoS appears in Fig. 1. For the global model, Wave Watch III (WW3 henceforth) is used and forced by a 6-hourly GFS meteo model, with a resolution of $1^{\circ} \times 1.25^{\circ}$. This global model generates 2-D wave spectra as output and will be used as swell boundary conditions for the nested models, as indicated in Fig. 1 by the arrows.

The next nested model is the Dutch Continental Shelf Model (DCSM), which comprises the wave model SWAN and the tide-surge model Delft3D-FLOW. The spatial resolution of the surge model is approximately $7.5 \times 10 \mathrm{~km}$, while the resolution of the wave model is approximately $15 \times 20 \mathrm{~km}$. The surge model is driven by meteo data from HIRLAM, which are 3-hourly data with approximately $9 \mathrm{x}$ $14 \mathrm{~km}$ resolution. In addition, amplitude and phase of several relevant tidal constituents are assigned using the tide model TPX072 (Egbert and Erofeeva, 2002). The SWAN model is forced by wind field from HIRLAM and the swell boundary conditions (area indicated by red lines in Fig. 2) are obtained from the global WW3 model. The models are run simultaneously, allowing for wave and tide-surge interactions. The model set-up of the DCSM model within CoSMoS is summarized in Table 2, and model version as well as the parameter settings used in the model are presented in Table 3. For the wave model, whitecapping is modelled based on Westhuysen et al. (2007), the bottom friction formula is from Hasselman et al. (1973), and the depth-induced breaking model is from Battjes and Janssen (1978). For the Delft3D FLOW model, uniform bed roughness coefficient is used, and wind drag coefficient is determined by a linear function of three break points and the corresponding wind speed (Delft3D FLOW User Manual). In this paper, The Dutch coast model and the local model will not be part of the analysis as we will focus on the application of CoSMoS for the North Sea.

The system is designed in a MATLAB platform, where the initiation and operational run are performed every 12 hours, and managed by the so-called timer loop. There are two timer loops in the system that dictates the operational run. First, the main loop, which defines the starting time and end time of model run, triggers the overall initiation of the system, and downloads necessary wind and air pressure data to be used by the models. The second time loop is the model loop, in which model runs will be executed in sequence, starting from global and regional models followed by higher-resolution models. Downloaded forcing data and simulation results from the models are stored on a local OPeNDAP server (OPeNDAP:
Open-source Project for a Network Data Access Protocol; Cornillon et al., 2003).

\section{Data and method}

The validation is carried out by comparing simulated parameters obtained from the model with the observed ones as ground truth. Statistical error measures are used to quantify the error between simulated and observed data. Here, root mean square error ( $e_{\mathrm{rms}}$ error), bias, and normalized error $\left(e_{\text {norm }}\right)$ are used. The expressions are as follows:

$e_{\text {rms }}=\left[\frac{1}{N} \sum_{i=1}^{N}\left(x_{i}-y_{i}\right)^{2}\right]^{\frac{1}{2}}$
bias $=\frac{1}{N} \sum_{i=1}^{N} x_{i}-\frac{1}{N} \sum_{i=1}^{N} y_{i}$
$e_{\text {norm }}=\frac{\left[\frac{1}{N} \sum_{i=1}^{N}\left[\left(x_{i}-\bar{x}\right)-\left(y_{i}-\bar{y}\right)\right]^{2}\right]^{\frac{1}{2}}}{\bar{y}}$.

In Eqs. (1)-(3), $N$ is the length of the time series parameter, $x$ and $y$ are simulated and observed parameter respectively, $\bar{x}$ and $\bar{y}$ are mean value of $x$ and $y$ respectively. For directional data, circular correlation and circular bias are used as statistical error measures. The circular bias is defined by subtracting the mean angular of the computed parameter from the mean angular of the observed. Here, the mean angular is computed by transforming the directional data into two vector components with magnitude of unity, and then taking the four quadrant inverse tangent of the resultant of the vectors as the mean angular (Berens, 2009). Circular correlation is computed by defining correlation coefficient of the directional data by also making use of the mean angular measures. Circular correlation (CC) and circular bias (CB) are defined as follows (Berens, 2009; Fisher, 1996):

$$
\begin{aligned}
& \mathrm{CC}=\frac{\sum_{i=1}^{N} \sin \left(x_{i}-\hat{x}\right) \sin \left(y_{i}-\hat{y}\right)}{\sqrt{\sum_{i=1}^{N} \sin ^{2}\left(x_{i}-\hat{x}\right) \sin ^{2}\left(y_{i}-\hat{y}\right)}} \\
& \mathrm{CB}=\hat{x}-\hat{y} \\
& \hat{x}=\arctan (R) \\
& \boldsymbol{R}=\frac{1}{N} \sum_{i=1}^{N}\left[\begin{array}{c}
\cos \left(m_{i}\right) \\
\sin \left(n_{i}\right)
\end{array}\right] .
\end{aligned}
$$

In Eqs. (4)-(7), $\hat{x}$ and $\hat{y}$ are the mean angular of simulated and observed parameter respectively, $(m, n)$ is the plane component of the directional data (unit vector), and $\boldsymbol{R}$ is the mean resultant vector. 
Table 4. Stations used in validation.

\begin{tabular}{llll}
\hline Station & Name & Abbreviation in this paper & Type \\
\hline B1 & Eierlandse Gat & EIELSGT & Directional wave buoy \\
B2 & Euro platform & EURPFM & Directional wave buoy \\
B3 & K13 platform & K13APFM & Directional wave buoy \\
T1 & Euro platform & EUR & Tidal gauge \\
T2 & Hoek van Holland & HvH & Tidal gauge \\
T3 & IJmuiden & IJM & Tidal gauge \\
T4 & Huibergat & HUI & Tidal gauge \\
T5 & K13 platform & K13 & Tidal gauge \\
\hline
\end{tabular}

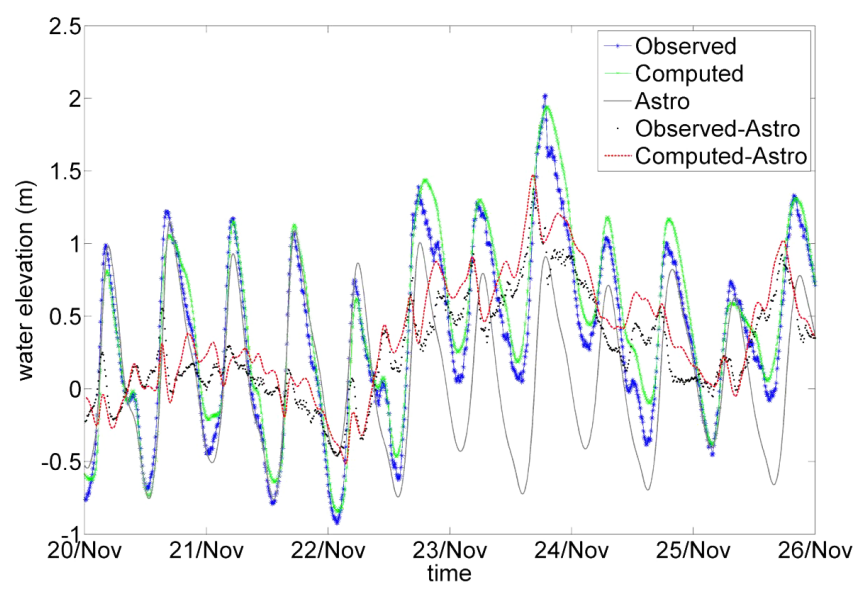

Figure 3. Water elevation for IJmuiden (IJM) during the storm in November 2009: blue - observed water level; green - computed water level; black - observed surge; red - computed surge; grey astronomical prediction.

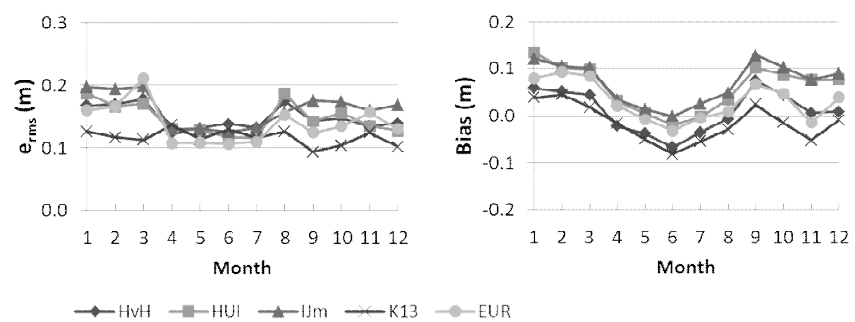

Figure 4. Monthly rms error (left) and bias (right) of surge elevation.

As the ground truth, data from deep-water directional wave buoys and tidal gauge record are used, of stations located near the Dutch coast. A total of three wave buoys are considered: Eierlandse Gat (EIELSGT), K13 Platform (K13APFM), and Euro Platform (EURPFM). For water levels, five gauges are used: Euro platform, Hoek van Holland, IJmuiden, Huibertgat, and K13 platform (Table 4 and Fig. 2). Data obtained from the buoys are processed, stored and retrievable as wave energy density, mean wave direction, and directional spreading as function of frequency, rather than the full 2-D spectra. Therefore, quasi 2-D wave energy spectrum is constructed using the following expressions:

$E(f, \theta)=E(f) \cdot D(\theta, f)$,

where $E(f, O)$ is the wave energy as a function of frequency and direction and $D$ is directional spreading. Since

$\iint E(f, \theta) d f d \theta=\int E(f) d f$

therefore,

$\int D(\theta, f) d \theta=1$.

For the directional spreading, a normal distribution function is used:

$D(\theta, f)=\frac{1}{\sigma \sqrt{2 \pi}} \exp \left[\frac{\left[\theta-\theta_{0}(f)\right]^{2}}{2 \sigma(f)^{2}}\right]$,

where $O_{0}(f)$ is mean direction as function of frequency, $\sigma$ is directional spreading as function of frequency, and $O$ is the running wave direction. Here we have to keep in mind that the shape of the directional spreading function is assumed to be Gaussian, and directional bimodality is not significant over the period of the data (Longuet-Higgins et al., 1963; Wenneker and Smale, 2013).

Since the wave model SWAN returns output as 2-D wave spectra as well, consistent parameter definitions can be used for both simulated and observed data. The integral wave parameters then will be calculated as follows:

$$
\begin{aligned}
& H_{\mathrm{m} 0}=4 \sqrt{\iint E(f, \theta) d f d \theta} \\
& T_{\mathrm{p}}=\frac{1}{f_{p}} .
\end{aligned}
$$

For the mean wave direction, formula from Kuik et al. (1988) is used:

$$
\theta_{\text {mean }}=\arctan \left[\frac{\iint \sin \theta E(f, \theta) d f d \theta}{\iint \cos \theta E(f, \theta) d f d \theta}\right] .
$$




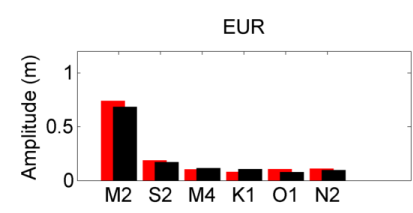

IJM
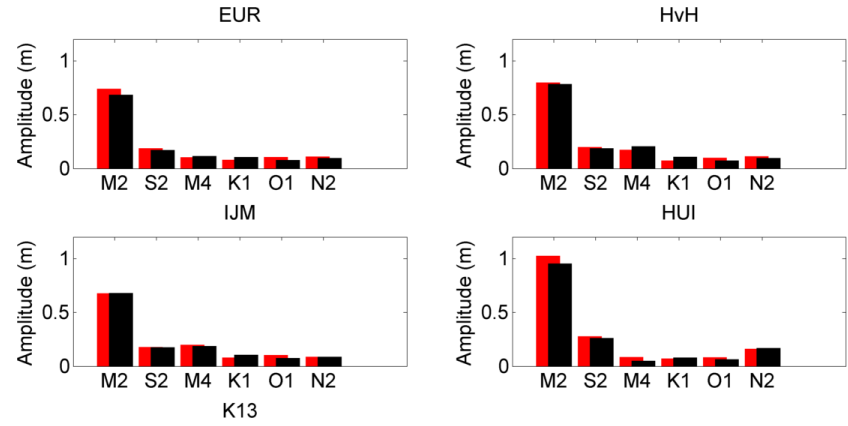

$\mathrm{HUI}$
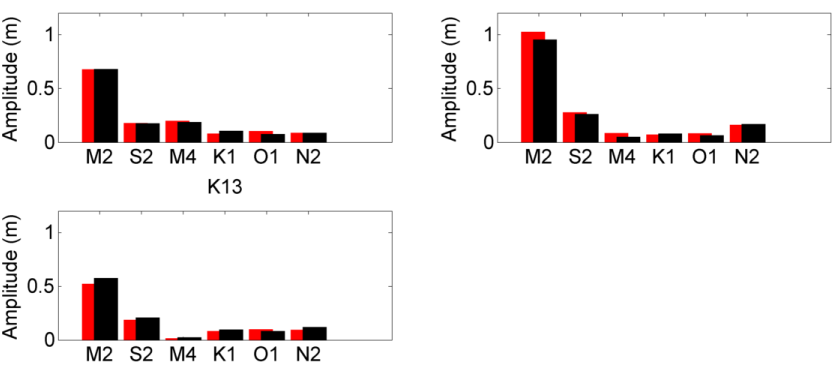

Figure 5. Tidal amplitude comparison for six tidal constituents: black - observation; red - computed.
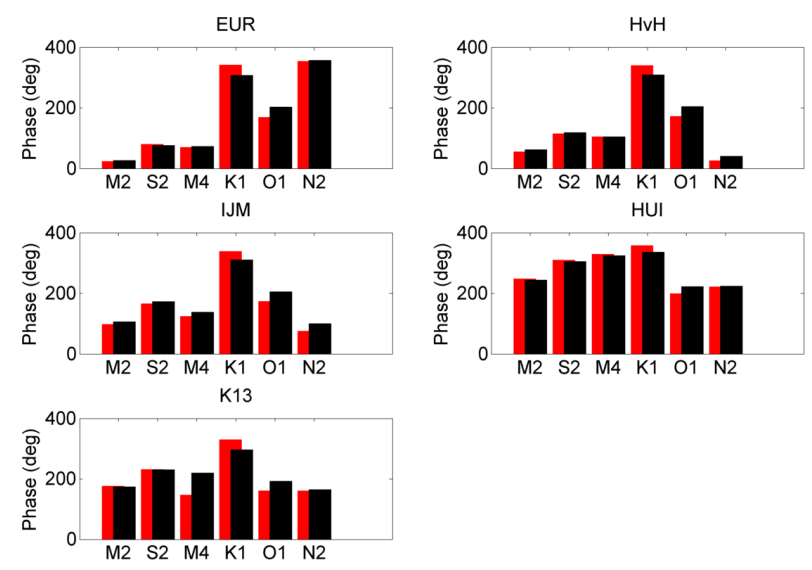

Figure 6. Tidal phase comparison for six tidal constituents: black observation; red - computed.

For analysis purposes, in addition to bulk wave parameters, wind sea and swell components will also be computed. To this end, an algorithm will be applied on the total wave spectrum to differentiate between energy that belongs to wind sea and swell. The algorithm will largely follow Portilla et al. (2009) and Hanson et al. (2009). Here, for simplification we make an assumption that the total energy content in the spectrum only consists of one system of wind sea and one system of swell. The demarcation line between sea and swell is defined as follows:

$f_{\mathrm{c}}=\frac{g}{2 \pi}[\alpha U \cos (\delta)]^{-1}$

$0 \leq \delta \leq \frac{\pi}{2}$,

where $f_{\mathrm{c}}$ is the critical frequency, $\alpha$ is a constant, $U$ is wind speed, and $\delta$ is the angle between wind sea and the wind. Energy content above this line will be counted as wind sea spectrum while below it is swell. The calibration parameter $\alpha$ of 1.8 is used.
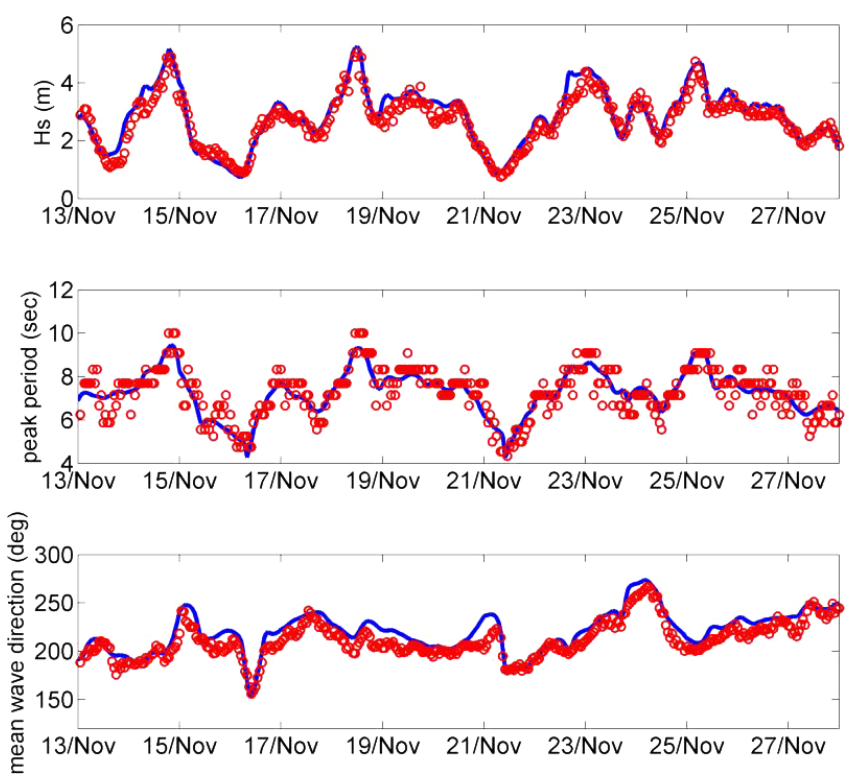

Figure 7. Time series of wave parameters: blue - model results; red circles - observations. Wave height (upper panel), peak period (middle), and mean wave direction (lower). Location: K13 platform.

\section{Results and discussion}

\subsection{Hindcast}

A hindcast was performed for the calendar year of 2009, where the forcing for the model system is provided by the analyzed wind fields. In general, the year 2009 exhibited typical yearly wave conditions for the North Sea without any particular significant storm event. As we are also interested in operational daily performance rather than specific extreme event analysis, this particular year is thus a representative one. Weekly averaged observed significant wave height varied from $0.5 \mathrm{~m}$ during week 27 (month of July) up to $2.8 \mathrm{~m}$ during week 48 (month of November). For the latter period, the maximum observed wave height was $4.79 \mathrm{~m}$. These wave heights are approximately in the same range for the three buoys considered.

\subsubsection{Water level and surge validation}

Model performance for water level and surge is analyzed by comparing both the simulated tidal signal and the surge with the observations. The surge levels were determined by subtracting astronomical prediction from the tidal signal. Results show that simulated tide and surge levels are in good agreement with observations. Figure 3 presents water levels plot for location IJmuiden during the storm that occurred in the last week of November 2009, where the computed water level (green) and observed water level (blue) elevates from astronomical prediction (grey). This water level raising is clearly seen from the observed surge level (black) which is 

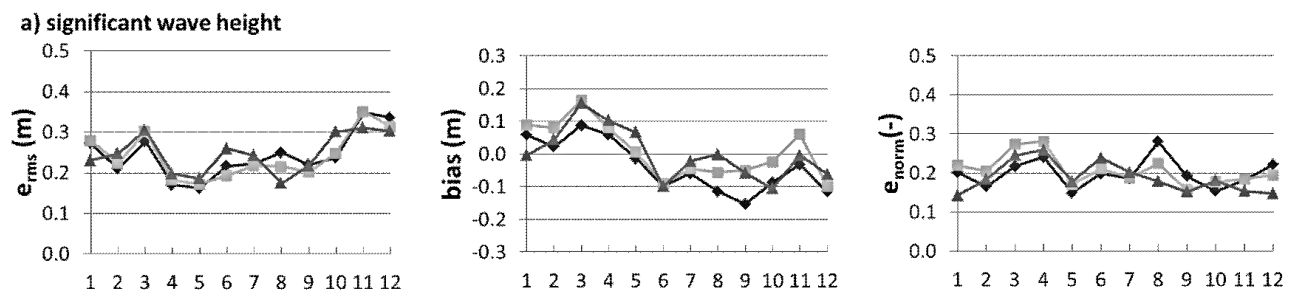

b) peak wave period
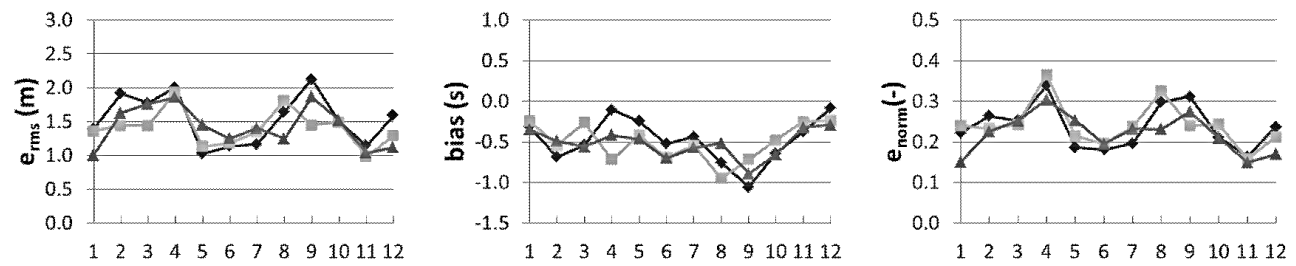

c) mean wave direction

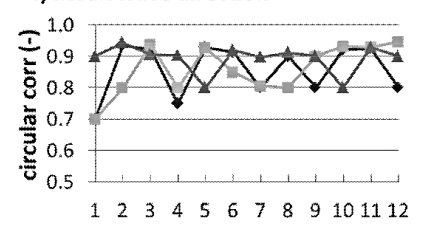

Month

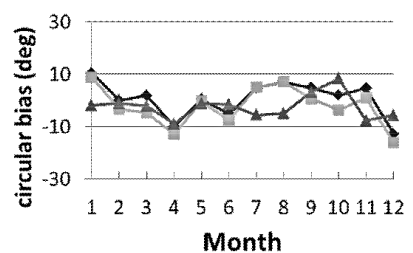

$\sim$ EIELSGT - EURPFM $\sim$ K13APFM

Figure 8. Monthly errors of wave parameters: (a) - wave height; (b) - peak period; (c) - mean wave direction.

in a good agreement with the computed surge (red). Monthly error plots for the surge levels appear in Fig. 4. Root mean square error (left panel) vary from $0.09 \mathrm{~m}$ for station $\mathrm{K} 13$ platform for the month of September, until $0.21 \mathrm{~m}$ for station Europlatform for the month of March. For the bias (right panel), the highest positive value is found at station Huibertgat for the month of February with a bias of $0.12 \mathrm{~m}$, while the strongest negative bias of $-0.08 \mathrm{~m}$ is given by station $\mathrm{K} 13$ platform for the month of June. The relatively higher surge rms error coincides with the winter period where stormier and higher wind speeds are expected. This seasonal trend is clearly seen in Fig. 4, where all the tidal gauges considered show a similar tendency of lower rms error during summer months with relatively higher rms error during the winter months. An exception is station K13 platform, where the rms error is relatively constant around $0.05-0.1 \mathrm{~m}$ over the year. This is due to the location of K13 platform which is relatively far offshore, which makes it less prone to the variability of wind-driven surge. In addition, the results also show that stronger positive bias is found mainly during the winter period, while during calmer months the absolute bias is relatively smaller with a tendency of being negative. Overall, the surge is in good agreement with observations over the year.

A tidal analysis was performed towards the computed water level where the amplitude and the phase of several relevant tidal constituents are compared with observations. Figure 5 presents a bar-plot of the tidal amplitude for six most dominant tidal constituents at the Dutch coast. For the most important constituent, the M2, model (red) tends to slightly over predict the observations (black), except for stations K13 platform. Relative error is from $0.4 \%$ for IJmuiden until $9 \%$ for K13 platform. Similar to Fig. 5, in Fig. 6 the bar-plot of tidal phase is presented. Tidal phase is predicted well by the model, with higher error tendency appears in diurnal constituents K1 and O1. Absolute differences between computed phase and observations for the most important constituent $\mathrm{M} 2$ is $2^{\circ}$ for $\mathrm{K} 13$ platform until $8^{\circ}$ for IJmuiden.

The error measures shown by the model verify that tide and total water level can be predicted very well by CoSMoS model. For the purpose of comparison with the similar coupled wave and tide-surge modelling approach, we calculate error metrics cost function CF and PBias (after Brown et al., 2010) of the CoSMoS model in predicting total water level and the surge. Over the whole tidal gauges used in the analysis, CoSMoS gives a PBias range of -1.68 until $-13.75 \%$ for total water level and -5.9 until $-41 \%$ for the surge. An 11-year hindcast of POLCOMS-WAM model applied for the Irish Sea by Brown et al. (2010) gives $\sim-1$ to $-14.9 \%$ for total water level and -3 to $-52 \%$ for the surge. Note that in Brown et al. (2010), a negative value of PBias suggests an overestimation tendency and vice versa, in contrast with one used in this paper. Error metric CF also gives good performance evaluation for CoSMoS. For total water level and surge, the ranges of CF value are 0.18-0.27 and 0.61-0.74, respectively $(\mathrm{CF}<1$ means the model has a chance of pre- 


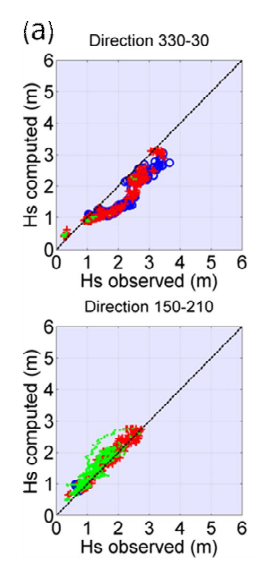

(b) Direction $330-30$

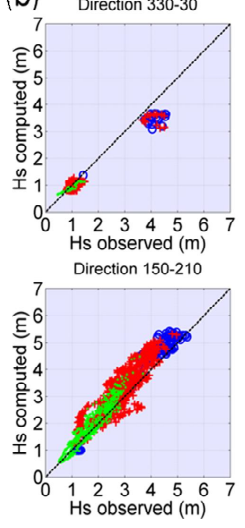

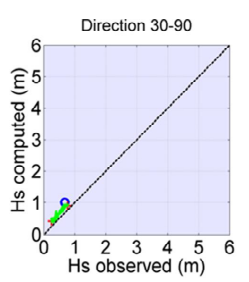

Direction 210-270
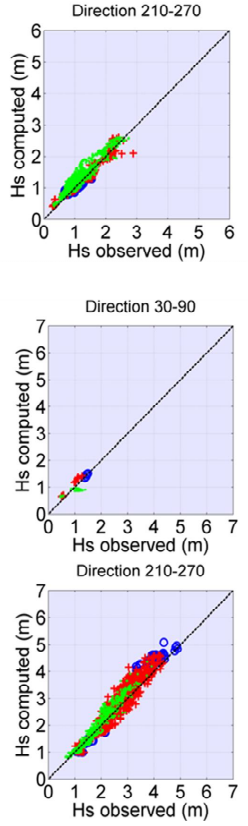

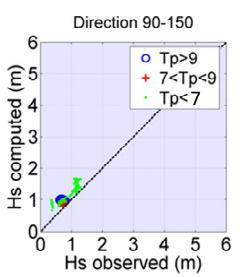

Direction $270-330$
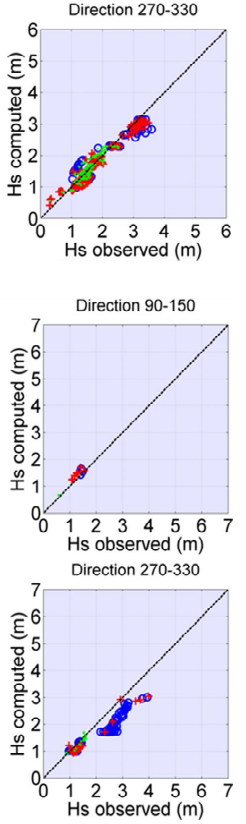

Figure 9. Scatter plot of observed significant wave height $H_{\mathrm{S}}$ versus computed, for every $60^{\circ}$ of observed incoming mean wave direction, for different peak wave period, $T_{\mathrm{p}}$. Green - observed $H_{\mathrm{S}}$ with $T_{\mathrm{p}}<7 \mathrm{~s}$; red $-7<T_{\mathrm{p}}<9 \mathrm{~s}$; blue $-T_{\mathrm{p}}>9 \mathrm{~s}$. (a) month of July, (b) month of November. Location: K13 platform.

dicting skill, $\mathrm{CF}<0.4$ means the models simulated the variables well).

\subsubsection{Wave validation}

In general, the wave model shows good skill in reproducing the wave parameters for the hindcast period. Examples of time series plots with simulated and observed wave parameters for K13 platform are presented in Fig. 7, where a storm occurred at the end of November. The wave height, peak period and mean wave direction computed by the wave model (blue) are in good agreement with the observations (red dots) over the 2-week period that is shown, with a slight overestimation tendency of the observed wave height by the model. Monthly wave parameter errors are given in Fig. 8 for all the buoys considered. Over the whole year, the rms error (Fig. 8a, left panel) ranges from $0.16 \mathrm{~m}$ (Eierlandse Gat, month of May) until $0.35 \mathrm{~m}$ (Europlatform, month of November). The normalized error for the wave height (Fig. 8a, right panel) is consistently below 0.3 with bias in a range of -0.15 to $0.15 \mathrm{~m}$ (Fig. $8 \mathrm{a}$, middle panel).

For the peak wave period (Fig. 8b), the rms error ranges from $1 \mathrm{~s}$ at the Europlatform buoy for the month of November, to $2.1 \mathrm{~s}$ at Eierlandse Gat for the month of September (Fig. 8b, left panel). The bias for the peak wave period is consistently negative (Fig. 8b, middle panel), ranging from -1.05 up to $-0.08 \mathrm{~s}$ for all buoys considered, suggesting that the model gives a consistent underestimation of peak wave period over the hindcast time. For the mean wave direction, model results show a significant agreement with the observations (Fig. 8c). The circular correlation varies from 0.7 at Europlatform and Eierlandse Gat during the month of January, up to 0.9 for the most of the months, showing a high correlation between the model result and the observation. Bias varies between $-16^{\circ}$ and $9^{\circ}$ with most of the months give bias approximately $\pm 10^{\circ}$.

The error measures show consistently low values, which are within the range of error metrics reported by Ferrarin et al. (2013) which uses a similar approach of coupling wave and tide-surge modelling. In addition, these results also show comparable skill with ones from Brown et al. (2010) whose applying similar coupling method to the Irish Sea. We calculate the error metrics $\mathrm{CF}$ for $\mathrm{CoSMoS}$, and obtain a relatively constant value of $\sim 0.3$ for $H_{\mathrm{s}}$, and $\sim 0.7$ for $T_{\mathrm{p}}$, over the 3 buoys analyzed, whilst Brown et al. (2010) obtain CF in the ranges of 0.4-0.6 and 1.4-4.0 for $H_{\mathrm{s}}$ and $T_{\mathrm{p}}$, respectively. This shows that CoSMoS demonstrates very good predictability skill. In Fig. 9, scatter plots of observed and computed wave height are presented, with different colours indicating different peak wave periods, for the station K13 platform during a relatively calm period (the month of June, Fig. 9a) and a stormy period (the month of November, Fig. 9b). Six panels scatter plot in (a) and (b) indicate $60^{\circ}$ bin of observed incoming wave direction. The results show that the wave model tends to underestimate northerly waves with peak wave period greater than $7 \mathrm{~s}$ (blue and red scatter dots in Fig. 9a top-left panel, in Fig. 9b top-left and bottom-right panel). For semi enclosed seas like the North Sea, the wave climate will be dominated by wind waves while occasional swells can be expected to be present that mainly come from the north, where the shelf is open to the northern part of the Atlantic Ocean. From the results, it is shown that for waves with peak period greater than $7 \mathrm{~s}$ and coming from the north (between 330 and 30 nautical degrees), there is a consistent tendency of the wave model to underestimate the wave height. In contrast, waves that come from west/south-west do not suffer from this underestimation (direction between 150 and $210^{\circ}$ and between 210 and $270^{\circ}$ in both Fig. 9a and b). This tendency is observed in all the buoys considered.

When the wave separation algorithm is applied, the swell and wind sea component results show fairly good agreement with observations. In Fig. 10 monthly error and bias of swell height component (upper row) and wind sea height component (lower row) are presented. For the wind sea component, the bias is between -0.14 and $0.19 \mathrm{~m}$ (middle panel lower row in Fig. 10), which is in contrast with the swell height bias 

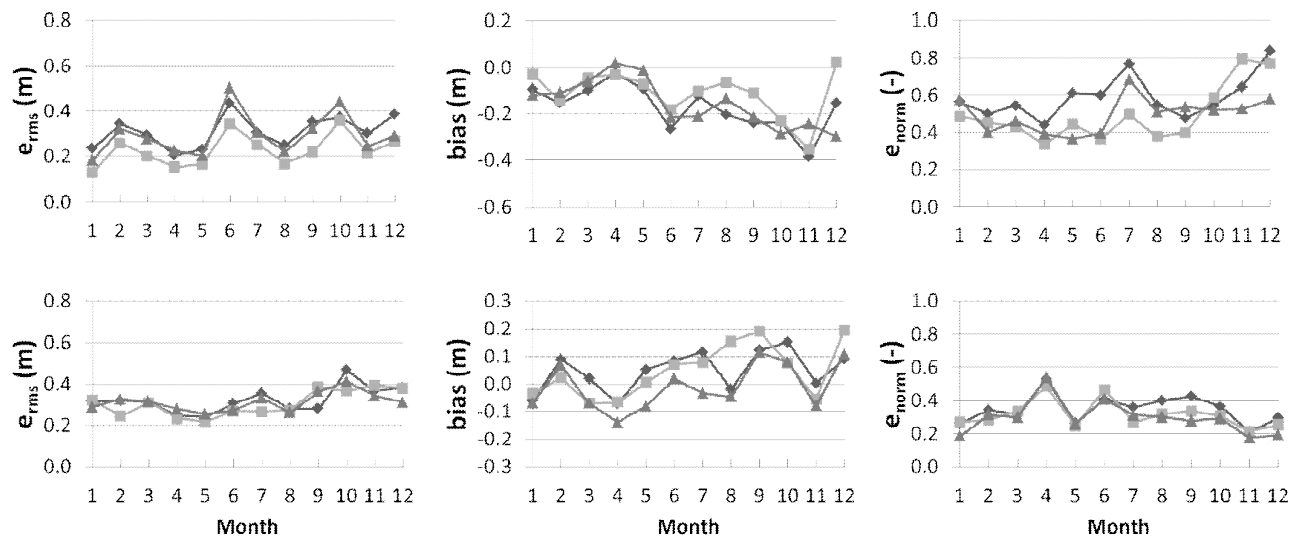

Figure 10. Monthly errors of swell height (first row) and wind sea component (second row).
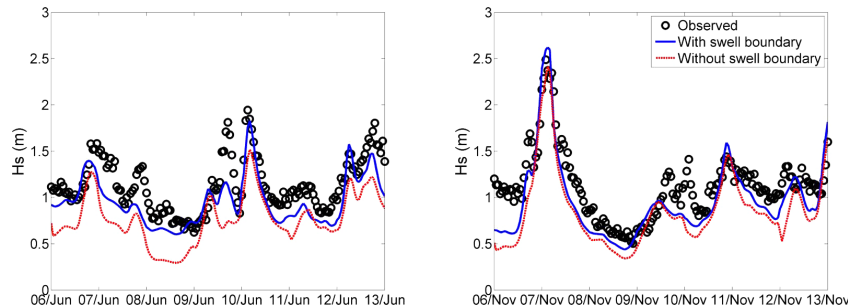

Figure 11. Significant wave height $H_{\mathrm{s}}$ for Eierlandse Gat for the month of June (left) and November (right): black - observed; blue - with swell boundary; red - without swell boundary.

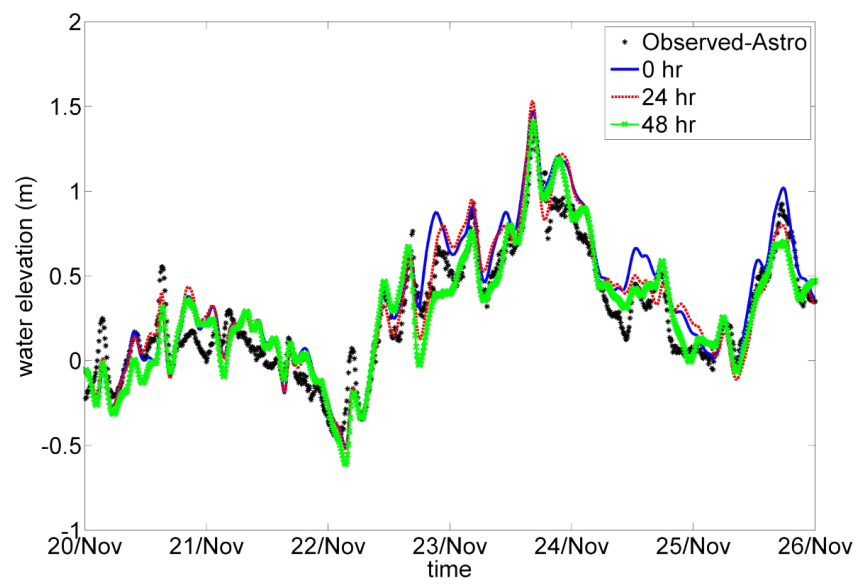

Figure 12. Surge elevation for IJmuiden during the November 2009 storm: blue - analyzed HIRLAM; red - $24 \mathrm{~h}$ HIRLAM; green - $48 \mathrm{~h}$ HIRLAM; black dots - observation.

that remains negative over the whole year (middle panel upper row in Fig. 10). This suggests again that the wave model underestimates swells, which may result in underestimation of northerly waves at the Dutch coast.

The lower frequency part of the total wave energy can be an important component for both daily normal conditions as
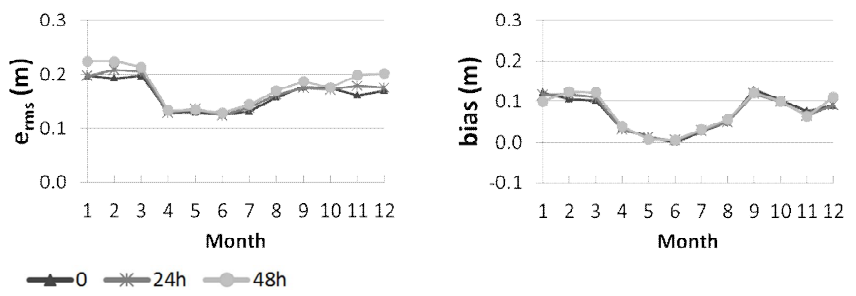

Figure 13. Monthly errors of surge elevation for different HIRLAM for location IJmuiden.

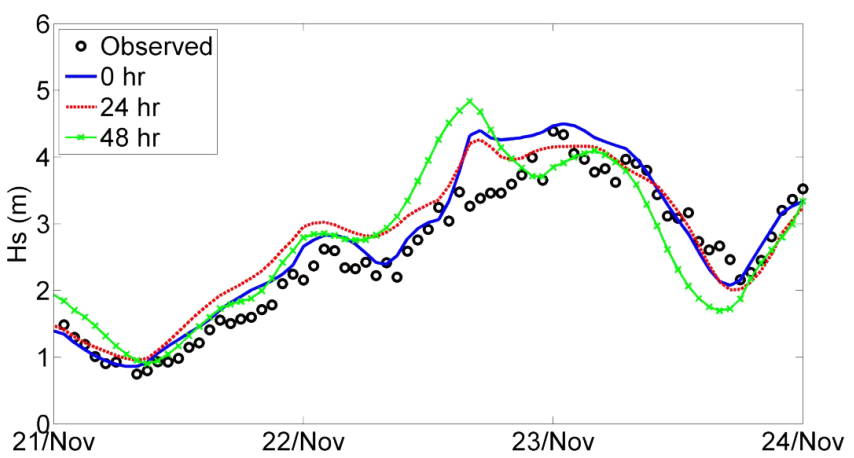

Figure 14. Significant wave height $H_{\mathrm{S}}$ for different HIRLAM input: blue - analyzed; red $-24 \mathrm{~h}$ forecast; green $-48 \mathrm{~h}$ forecast; black circles - buoy. Location: K13 platform.

well as storm periods. For normal conditions, several studies use swell-component height as one of the parameters in their statistical predictions system of rip currents, which were built based on the correlation between wave conditions and number of beach rescue due to drowning (Lushine, 1991; Lascody, 1998; Engle et al., 2002). This opens doors for the future works on improving the wave model as well as the swell boundary. 

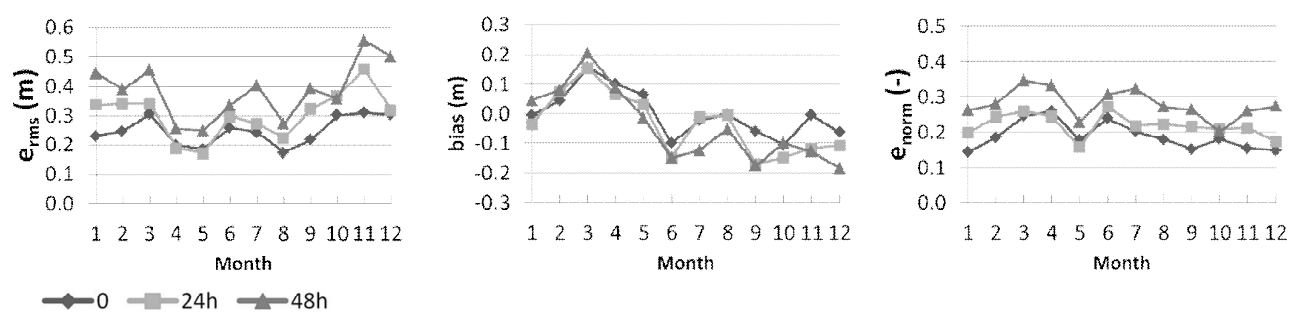

Figure 15. Monthly error of significant wave height $H_{\mathrm{S}}$ for different HIRLAM input. Location: K13 platform.

\subsubsection{Effect of swell boundary as model system component}

The CoSMoS system applies the global WAVEWATCH III model to derive the swell boundary conditions for the DCSM model (red lines in Fig. 2). Here, a simulation is performed where we ignore the swell boundary and use only wind forcing from HIRLAM as the main input into the wave model to see the effect of such a scenario. The result shows that model performance degrades after removal of the swell boundary with different reactions from the model for different periods. Figure 11 presents time series of wave height with and without the swell boundary for the month of June (left panel) and the month of November (right panel) for station Eierlandse Gat. During the month of June (Fig. 11 left panel), the degradation after ignoring the swell boundary is fairly significant, where the simulation result (red) suffers more underestimation compared to the default setting of the model system (blue). The normalized rms error increases (on average over the buoys) by $34 \%$. In contrast, during the month of November (Fig. 11 right panel), the effect on negating the swell boundary is 2 times less than the month of June, with a $15 \%$ increase in normalized rms error.

\subsection{Validation in forecast mode}

In order to assess the capability of CoSMoS to predict events a number of days into the future, a forecast mode validation is performed where the model system is forced by HIRLAM forecast winds of the year 2009. Two types of forecast HIRLAM wind fields are considered: a $24 \mathrm{~h}$ forecast and a $48 \mathrm{~h}$ forecast. Figure 12 shows an example of surge elevation plots for different HIRLAM inputs together with the observations for IJmuiden during November 2009. Results using the HIRLAM forecasts both for 24 and $48 \mathrm{~h}$ ahead (red and green line respectively) retain good agreement with observations (black dots). Differences are relatively small between results using analyzed wind (blue) and results using either the 24 or $48 \mathrm{~h}$ forecasted wind. Monthly error plots of surge elevation for different HIRLAM are shown in Fig. 13 for station IJmuiden. A strong seasonal feature is retained where a relatively lower rms error and bias exhibited during the summer season while stronger bias is seen during the summer period. This greatest rms error increase is 33 percent (from analyzed to $48 \mathrm{~h}$ ) for the month of December. On average, the rms error increases by $11 \%$ (from analyzed to $24 \mathrm{~h}$ ) and $25 \%$ (from analyzed to 48 hours) for all stations.

For the wave model, time series of wave heights for different HIRLAM forcings are presented in Fig. 14, for 5 days in the last week of November for location K13 platform, when the highest weekly averaged wave heights were observed. The forecast results (red: $24 \mathrm{~h}$, green: $48 \mathrm{~h}$ ) are also in good agreement with observations (black dots). However, there are clear differences, especially with the 48 hour HIRLAM forecasts, while results using analyzed and $24 \mathrm{~h}$ HIRLAM look relatively similar. Monthly errors of significant wave height for different HIRLAM are shown in Fig. 15 for location K13 platform. The rms error tends to increase as the forecast horizon increases. For instance at K13 platform for the month of November, the rms error was $0.31 \mathrm{~m}$ with analyzed wind, and further increased to 0.46 and $0.56 \mathrm{~m}$ with 24 and $48 \mathrm{~h}$ winds, respectively. On average, stronger error increments are more prominent during the winter period. In contrast, the monthly averaged bias does not increase strongly as the forecast horizon increases. On average, the rms error increases by 20 and $40 \%$ for 24 and $48 \mathrm{~h}$ forecast, respectively for all locations.

\section{Conclusions}

A CoSMoS model system covering the North Sea is built which employ coupled wave and tide-surge modelling approach to hindcast and forecast wave conditions and water levels for the area along the Dutch coast. The system is designed in a generic way to accommodate and integrate different regional and local models. A validation is performed of the Dutch Continental Shelf Model (DCSM) covering the North Sea, using wave buoys and tidal gauges available along the Dutch coast. Hindcast results show that the surge elevation produced by the model is in good agreement with the observations, with rms error ranging from 0.09 to $0.21 \mathrm{~m}$. On average, the model tends to slightly overestimate surge levels, especially during the winter months. For the wave model, simulated wave parameters agree well with observations, with a relative error of 14 until $30 \%$. However, model tends to underestimate swell height. Using default settings of the model system (swell boundary is included), a consistent underestimation is found for northerly waves with relatively 
low frequency, which is also supported by the wave separation algorithm. This suggests room for improvement for the swell boundary conditions to the North of the model domain.

In order to test the CoSMoS system in forecast mode, it has been forced by HIRLAM 24 and $48 \mathrm{~h}$ forecasts. The model system is capable of predicting high wave events and storm surge up to 2 days in advance. However, the performance does degrade as the forecast horizon increases. A smaller error increase is found for the surge elevation than for the wave heights. For surge elevation, on average, the rms error increases by $11 \%$ (from analyzed to $24 \mathrm{~h}$ ) and $25 \%$ (from analysed to $48 \mathrm{~h}$ ) for all stations. On the other hand, for the wave model, the rms error increases on average by 20 and $40 \%$ for 24 and $48 \mathrm{~h}$ forecast, respectively.

To summarize, we conclude that the CoSMoS Dutch Continental Shelf Model is a fit-for-purpose regional model to simulate waves, tide and surge, including the interactions, and to provide boundary conditions for coastal models with which we can use as coastal monitoring tools.

In the future, merging CoSMoS with a more integrated operational forecast system like FEWS is recommended in order to more accurately predict storm surge level because introducing data assimilation into the system will increase forecast quality.

Acknowledgements. This research has been carried out in the framework of project: Real-Time Safety on Sedimentary Coasts funded by the Flood Control 2015 research program (project code 2010.05), and the Deltares' strategic research program "Eventdriven Hydro- and Morphodynamics" (project code 1202362). The authors thank Ivo Wenneker and Alfons Smale for valuable discussions, also for providing buoy data and useful algorithms that are used in this work.

Edited by: B. D. Malamud

\section{References}

Baart, F., van der Kaaij, T., van Ormondt, M., van Dongeren, A., van Koningsveld, M., and Roelvink, J. A.: Real-time forecasting of morphological storm impacts: a case study in The Netherlands, J. Coast. Res., Special Issue, 56, 1617-1621, 2009.

Barnard, P., O’Reilly, B., van Ormondt, M., Elias, E., Ruggiero, P., Erikson, L., Hapke, C., Collins, B. D., Guza, R. T., Adams, P. N., and Thomas, J. T.: The framework of a coastal hazards model; a tool for predicting the impact of severe storms, U.S. Geological Survey Open-File Report 2009-1073, 21 pp., 2009.

Battjes, J. A. and Janssen, J. P. F. M.: Energy loss and set-up due to breaking of random waves, 16th Int. Conf. Coast. Eng., ASCE, 569-587, 1978.

Behrens, A. and Günther, H.: Operational wave prediction of extreme storms in Northern Europe, Nat. Hazards, 49, 387-399, 2009.

Berens, P.: CircStat: A MATLAB Toolbox for Circular Statistics, J. Stat. Softw., 31, 1-21, 2009.
Bertotti, L. and Cavaleri, L.: Wind and wave predictions in the Adriatic Sea, J. Marine Syst., 78, S227-S234, 2009.

Bertotti, L., Canestrelli, P., Cavaleri, L., Pastore, F., and Zampato, L.: The Henetus wave forecast system in the Adriatic Sea, Nat. Hazards Earth Syst. Sci., 11, 2965-2979, doi:10.5194/nhess-112965-2011, 2011.

Booij, N., Ris, R. C., and Holthuijsen, L. H.: A third-generation wave model for coastal regions 1 . Model description and validation, J. Geophys. Res., 104, 7649-7666, 1999.

Brown, J. M. and Wolf, J.: Coupled wave and surge modelling for the eastern Irish Sea and implications for model wind-stress, Cont. Shelf Res., 29, 1329-1342, 2009.

Brown, J. M., Souza, A. J., and Wolf, J.: An 11-year validation of wave-surge modelling in the irish sea, using a nested polcomswam modelling system, Ocean Model., 33, 118-128, 2010.

Cavaleri, L. and Bertotti, L.: Accuracy of the modelled wind and wave fields in enclosed seas, Tellus A-Dyn. Meteorol. Oceanogr., 56, 167-175, 2004.

Cavaleri, L. and Bertotti, L.: The improvement of modelled wind and wave fields with increasing resolution, Ocean Eng., 33, 553$565,2006$.

Cherneva, Z., Andreeva, N., Pilar, P., Valchev, N., Petrova, P., and Guedes Soares, C.: Validation of the WAMC4 wave model for the Black Sea, Coast. Eng., 55, 881-893, 2008.

Cornillon, P., Gallagher, J., and Sgouros, T.: OPeNDAP: Accessing data in a distributed, heterogeneous environment, Data Sci. J., 2, 164-174, 2003.

De Kleermaeker, S., Verlaan, M., Kroos, J., and Zijl, F.: A new coastal flood forecasting system for The Netherlands, Hydro12 - Taking care of the sea, Rotterdam, 2012.

Deltares: Simulation of multi-dimensional hydrodynamic flows and transport phenomena, including sediments, DELFT3D-FLOW User Manual, 2013.

Egbert, G. D. and Erofeeva, S. Y.: Efficient Inverse Modeling of Barotropic Ocean Tides, J. Atmos. Ocean. Technol., 19, 183204, 2002.

Engle, J., MacMahan, J. H., Thieke, R. J., Hanes, D. M., and Dean, R. G.: Formulation of a rip current predictive index using rescue data, National Conference on Beach Preservation Technology, Biloxi, 23-25, 2002.

Ferrarin, C., Roland, A., Bajo, M., Umgiesser, G., Cucco, A., Davolio, S., Buzzi, A., Malguzzi, P., and Drofa, O.: Tide-surge-wave modelling and forecasting in the Mediterranean Sea with focus on the Italian Coast, Ocean Model., 61, 38-48, 2013.

Fisher, N. I.: Statistical Analysis of Circular Data, Cambridge University Press, 296 pp., 1996.

Gerritsen, H., de Vries, J. W., and Philippart, M. E.: The Dutch Continental Shelf Model, in: In Quantitative Skill Assesment for Coastal Ocean, edited by: Lynch, D. and Davies, A., American Geophysical Union, Washington DC, 425-467, 1995.

Gunther, H.: WAM Cycle 4.5., Institute for Coastal Research, GKSS Research Centre, Germany, 40 pp., 2002.

Hanson, J. L., Tracy, B. A., Tolman, H. L., and Scott, R. D.: Pacific Hindcast Performance of Three Numerical Wave Models, Journal of Atmospheric and Oceanic Technology, 26, 1614-1633, 2009.

Hasselman, K., Barnett, T. P., Bouws, E., Carlson, D. E., and Hasselmann, P.: Measurements of wind-wave growth and swell 
decay during the Joint North Sea Wave Project (JONSWAP), Deutsche Hydrographische Zeitschrift, 8, 95 pp., 1973.

Heemink, A. W. and Kloosterhuis, H.: Data assimilation for nonlinear tidal models, Int. J. Num. Meth. Fluids, 11, 1097-1112, 1990.

Janssen, P. A. E. M., Hansen, B., and Bidlot, J.-R.: Verification of the ECMWF Wave Forecasting System against Buoy and Altimeter Data, Weather Forecast., 12, 763-784, 1997.

Kuik, A. J., van Vledder, G. P., and Holthuijsen, L. H.: A Method for the Routine Analysis of Pitch-and-Roll Buoy Wave Data, J. Phys. Oceanogr., 18, 1020-1034, 1988.

Lascody, R. L.: East central florida rip current program, National Weather Digest, 25-30, 1998.

Longuet-Higgins, M. S. and Stewart, R. W.: A note on wave set-up, J. of Marine Res., 21, 4-10, 1963.

Lushine, J. B.: A study of rip currents drownings and related weather factors, National Weather Digest, 13-19, 1991.

Mazarakis, N., Kotroni, V., Lagouvardos, K., and Bertotti, L.: High-resolution wave model validation over the Greek maritime areas, Nat. Hazards Earth Syst. Sci., 12, 3433-3440, doi:10.5194/nhess-12-3433-2012, 2012.

Ponce de León, S., and Guedes Soares, C.: Sensitivity of wave model predictions to wind fields in the Western Mediterranean sea, Coast. Eng., 55, 920-929, 2008.

Portilla, J., Ocampo-Torres, F. J., and Monbaliu, J.: Spectral Partitioning and Identification of Wind Sea and Swell, J. Atmos. Ocean. Technol., 26, 107-122, 2009.

Resio, D. and Perrie, W.: Implications of an $f-4$ Equilibrium Range for Wind-Generated Waves, J. Phys. Ocean., 19, 193-204, 1989.

Roelvink, D., Reniers, A., van Dongeren, A., van Thiel de Vries, J., McCall, R., and Lescinski, J.: Modelling storm impacts on beaches, dunes and barrier islands, Coast. Eng., 56, 1133-1152, 2009.

Stelling, G.: On the construction of computational methods for shallow water flow problems, Rijkswaterstaat communication, no. 35, The Hague, 1984.

Tolman, H. L.: User manual and system documentation of WAVEWATCH-III version 3.14, 2009.
Unden, P., Rontu, L., Jarvinen, H., Lynch, P., Calvo, J., Cats, G., Cuxart, J., Eerola, K., Fortelius, C., Garcia-Moya, J., Jones, C., Lenderlink, G., McDonald, A., McGrath, R., Navascues, B., Nielsen, N., Odegaard, V., Rodriguez, E., Rummukainen, M., Room, R., Sattler, K., Sass, B., Savijarvi, H., Schreur, B., Sigg, R. The, H., and Tijm, A.: HIRLAM-5 Scientific Documentation, 144 pp., 2002.

Van Dongeren, A., Sancho, F. E., Svendsen, I. A., and Putrevu, U.: SHORECIRC: A quasi 3-D Nearshore Model, Coast. Eng., 2741-2754, 1994.

Van Dongeren, A., Van Ormondt, M., Sembiring, L., Sasso, R., Austin, M., Briere, C., Swinkels, C., Roelvink, D., and Van Thiel de Vries, J.: Rip current predictions through model data assimilation on two distinct beaches, Coastal Dynamics, Bordeaux, France, 2013.

Van Ormondt, M., Van Dongeren, A., Briere, C., Sembiring, L., Winter, G., Lescinski, J., and Swinkels, C.: Simulating storm impacts and coastal flooding along the Netherlands Coast, Flood Risk 2012, Rotterdam, the Netherlands, 28-29,, 2012.

Verlaan, M., Zijderveld, A., de Vries, H., and Kroos, J.: Operational storm surge forecasting in the Netherlands: developments in the last decade, Philosophical Transactions of the Royal Society A: Mathematical, Phys. Eng. Sci., 363, 1441-1453, 2005.

Wei, G., Kirby, J. T., Grilli, S. T., and Subramanya, R.: A fully nonlinear Boussinesq model for surface waves. Part 1. Highly nonlinear unsteady waves, J. Fluid Mech., 294, 71-92, 1995.

Wenneker, I. and Smale, A.: Measurement of 2D wave spectra during a storm in a tidal inlet, Coast. Dynam., France, 2013.

Werner, M., Schellekens, J., Gijsbers, P., van Dijk, M., van den Akker, O., and Heynert, K.: The Delft-FEWS flow forecasting system, Environ. Modell. Softw., 40, 65-77, 2013.

Westhuysen, A. J., Zijlema, M., and Battjes, J. A.: Nonlinear saturation-based whitecapping dissipation in SWAN for deep and shallow water, Coast. Eng., 54, 151-170, 2007.

Wolf, J.: Coupled wave and surge modelling and implications for coastal flooding, Adv. Geosci., 17, 19-22, 2008, http://www.adv-geosci.net/17/19/2008/. 